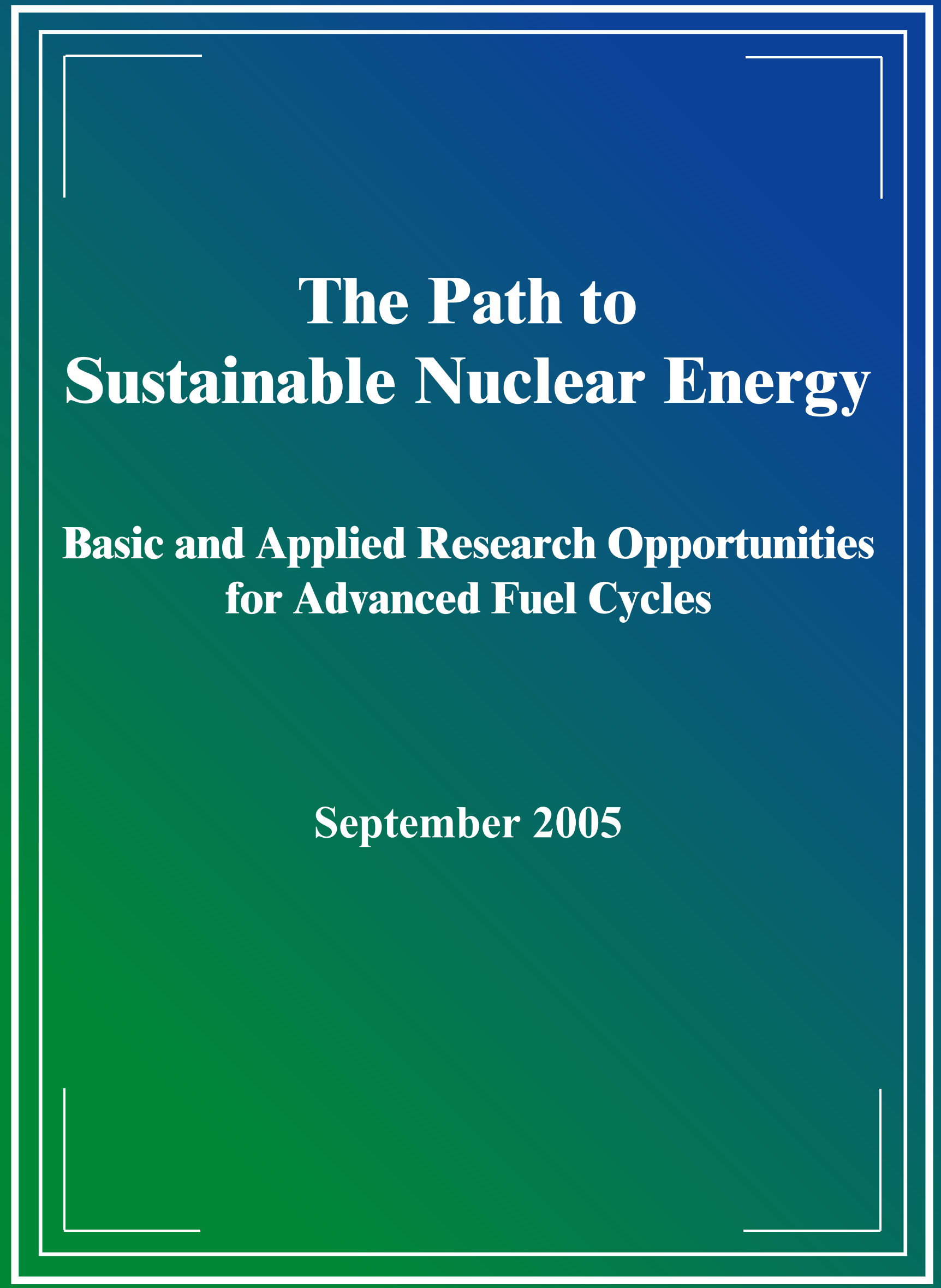




\section{The Path to Sustainable Nuclear Energy Basic and Applied Research Opportunities for Advanced Fuel Cycles}




\section{CONTENTS}

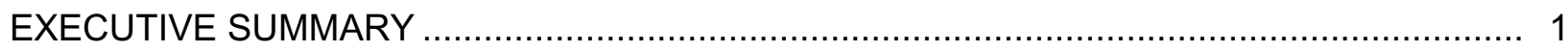

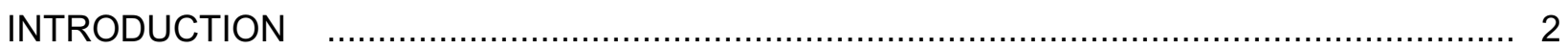

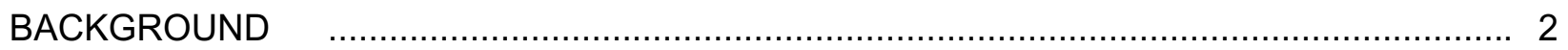

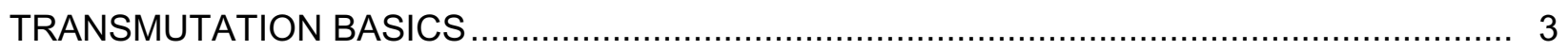

PROPOSED FUEL CYCLES: ONGOING R\&D AND POTENTIAL CHALLENGES …............ 6

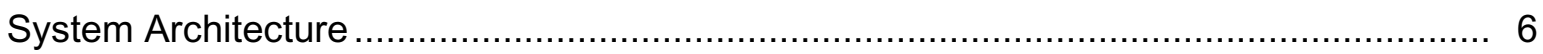

Technology Choices for Advanced Fuel Cycles...................................................... 7

R\&D Timeline and Potential Challenges ………………......................................... 8

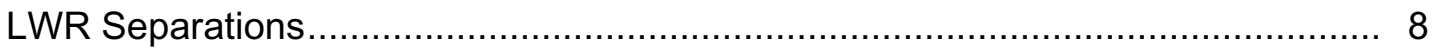

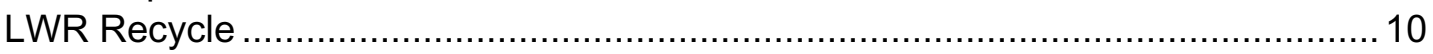

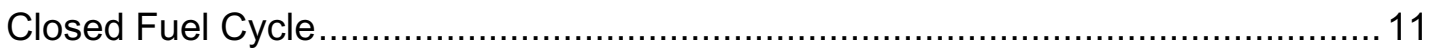

POTENTIAL CONTRIBUTIONS OF BASIC SCIENTIFIC RESEARCH TO

ADVANCED FUEL CYCLE INITIATIVE TECHNOLOGIES …........................................... 12

Translational Tools Needed to Advance AFCl Objectives …….................................... 12

Potential Impacts of Translational Tools on AFCl Challenges ........................................ 13

SCIENCE AREAS THAT IMPACT THE ADVANCED FUEL CYCLE INITIATIVE .....................14

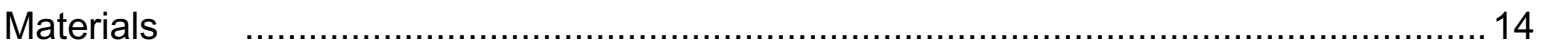

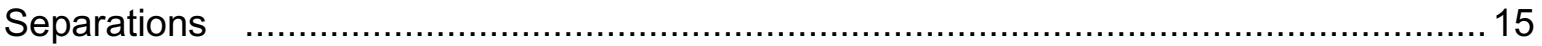

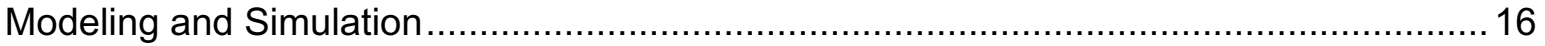

Proliferation Resistance of the Overall Nuclear Cycle ................................................. 17

REFERENCES

ACRONYMS

WORKSHOP BACKGROUND, ORGANIZERS, and PARTICIPANTS ................................. 20 


\section{EXECUTIVE SUMMARY}

The objective of this report is to identify new basic science that will be the foundation for advances in nuclear fuel-cycle technology in the near term, and for changing the nature of fuel cycles and of the nuclear energy industry in the long term. The goals are to enhance the development of nuclear energy, to maximize energy production in nuclear reactor parks, and to minimize radioactive wastes, other environmental impacts, and proliferation risks.

The limitations of the once-through fuel cycle can be overcome by adopting a closed fuel cycle, in which the irradiated fuel is reprocessed and its components are separated into streams that are recycled into a reactor or disposed of in appropriate waste forms. The recycled fuel is irradiated in a reactor, where certain constituents are partially transmuted into heavier isotopes via neutron capture or into lighter isotopes via fission. Fast reactors are required to complete the transmutation of long-lived isotopes. Closed fuel cycles are encompassed by the Department of Energy's Advanced Fuel Cycle Initiative (AFCl), to which basic scientific research can contribute.

Two nuclear reactor system architectures can meet the AFCl objectives: a "single-tier" system or a "dual-tier" system. Both begin with light water reactors and incorporate fast reactors. The "dual-tier" systems transmute some plutonium and neptunium in light water reactors and all remaining transuranic elements (TRUs) in a closed-cycle fast reactor.

Basic science initiatives are needed in two broad areas:

- Near-term impacts that can enhance the development of either "single-tier" or "dual-tier" $\mathrm{AFCl}$ systems, primarily within the next 20 years, through basic research. Examples:

o Dissolution of spent fuel, separations of elements for TRU recycling and transmutation

o Design, synthesis, and testing of inert matrix nuclear fuels and non-oxide fuels

0 Invention and development of accurate on-line monitoring systems for chemical and nuclear species in the nuclear fuel cycle

o Development of advanced tools for designing reactors with reduced margins and lower costs

- Long-term nuclear reactor development requires basic science breakthroughs:

o Understanding of materials behavior under extreme environmental conditions

o Creation of new, efficient, environmentally benign chemical separations methods

o Modeling and simulation to improve nuclear reaction cross-section data, design new materials and separation system, and propagate uncertainties within the fuel cycle

o Improvement of proliferation resistance by strengthening safeguards technologies and decreasing the attractiveness of nuclear materials

A series of translational tools is proposed to advance the $\mathrm{AFCl}$ objectives and to bring the basic science concepts and processes promptly into the technological sphere. These tools have the potential to revolutionize the approach to nuclear engineering R\&D by replacing lengthy experimental campaigns with a rigorous approach based on modeling, key fundamental experiments, and advanced simulations. 


\section{The Path to Sustainable Nuclear Energy Basic and Applied Research Opportunities for Advanced Fuel Cycles}

\section{Introduction}

Basic research conducted in the early and middle years of the $20^{\text {th }}$ century created the scientific foundation for the development of the nuclear energy systems that provide twenty percent of U.S. electricity (and about $17 \%$ globally) today. The last third of the $20^{\text {th }}$ century saw a decline in the amount of fundamental research directed at this essential sector of our scientific infrastructure in favor of expenditures on more applied problems in nuclear technology and other fundamental scientific priorities. It is becoming increasingly evident that prospective shortages in energy supplies and concerns about the global climate favor a resurgence of interest in nuclear power. As this interest intensifies toward societal action, science now faces an unprecedented opportunity to effect dramatic changes. It is thus the objective of this report to indicate how new basic science can provide the foundation for significant advances in fuel-cycle technology in the near term, and for changing the nature of fuel cycles and of the nuclear energy industry in the long term.

Nuclear energy is expected to grow significantly, both nationally and globally, to meet future energy demand. This growth should proceed with a goal of zero emissions. The roughly 400 nuclear reactors operating worldwide are supported by a fuel cycle that starts with uranium mining and ends with (planned) disposal of nuclear waste in geologically-stable environments. Today, basic and applied research is poised to replace the significant degree of empiricism and phenomenology that have been employed in nuclear design and implementation efforts heretofore. However, full development of a science-based approach for nuclear reactor and fuel cycle technology and systems is a true "grand challenge". It encompasses the entirety of the physical sciences and will test the limits of theory, computational modeling, and experimental methodology. The fundamental objective must be to accumulate enough understanding of the scientific subsystems to enable rational design of a nuclear-fission-based energy production system that has no significant environmental impact.

\section{Background}

The current fuel cycle deployed in the U.S. and most other countries is a once-through cycle: nuclear fuel is fabricated from mined and enriched uranium, irradiated once in a reactor, and then eventually disposed of in a geologic repository. Open fuel cycles have been deployed commercially for more than three decades and have proven to be safe, environmentally sound, and economically attractive, although waste management policies have not been fully implemented and no geologic repositories have opened to serve as the ultimate location for the disposal of wastes. 
Natural uranium contains $0.7 \% \mathrm{U}-235$ and $99.3 \% \mathrm{U}-238$. It is enriched up to $5 \% \mathrm{U}-235$ for fresh light water reactor (LWR) fuel. Spent nuclear fuel contains about $95 \%$ uranium (mostly U-238), more than $3 \%$ fission products, and less than $2 \%$ transuranics (neptunium, plutonium, americium, and curium). All actinides present in the spent fuel have potential value for energy generation.

As world dependence on nuclear energy increases-which it is bound to do-these open fuel cycles will not meet long-term sustainability goals.

- They use only a small fraction (less than $1 \%$ ) of the energy available in the original mined uranium.

- They discharge into the environment long-term radiotoxic elements (most importantly, the transuranic isotopes (TRUs)) that must be contained for hundreds of thousands of years.

- The construction and licensing of geologic repositories for final disposal has been a politically difficult proposition in all industrialized countries that have attempted it. The radiological content ("loading") of repositories is limited by two physical phenomena:

o the potential dose to the population (for Yucca Mountain, dose would first be dominated by long-lived fission products technetium-99 and iodine-129, and in the long term would be dominated by neptunium-237, occurring primarily as a decay product of plutonium-241/americium-241) and

o the long-term heat load generated over the first 1,500 years after repository closure by three transuranic isotopes: plutonium-238, plutonium-241, and americium-241.

These difficulties can be overcome by adopting a closed fuel cycle, in which the irradiated fuel is reprocessed, and its constituent elements are separated into streams to be recycled into a reactor or disposed of in appropriate waste forms. The recycled fuel is then irradiated in a reactor, where certain constituent elements are partially transmuted into higher-atomic-number elements via neutron capture or into lower-atomic-number elements via fission. The fuel is then reprocessed in a closed-loop cycle.

\section{Transmutation Basics}

Neutronic transmutation occurs when a long-lived fission product or a transuranic isotope interacts with a neutron to produce, via capture or fission (followed by decay), new isotopes that will eventually fission. Figure 1 illustrates the transmutation process for the TRUs in a thermal spectrum.

Neutrons are readily available for transmutation from two sources-thermal reactors (such as a pressurized-water reactor, PWR) and fast reactors (such as a sodium-cooled fast reactor, SFR).

The transmutation performance of these two reactor systems is represented in Figure 2, which shows the ratio of the fission probability to the capture probability in each type of reactor. 


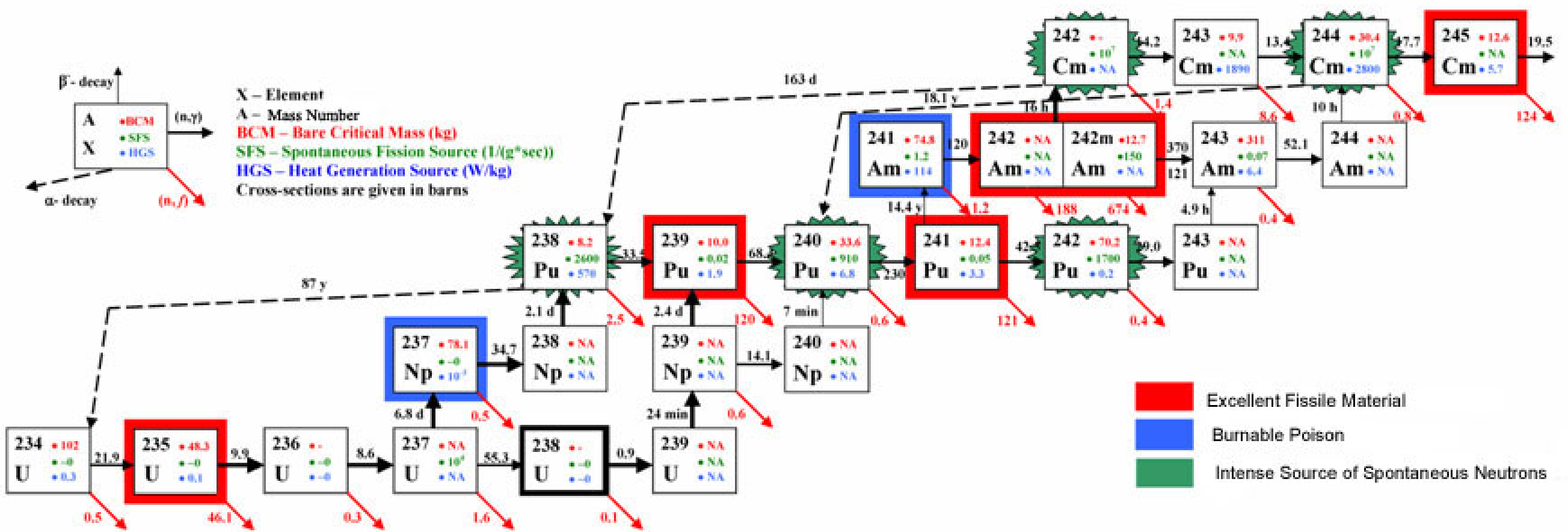

Figure 1. Main Transformations in Advanced U-TRU Fuels [1] 


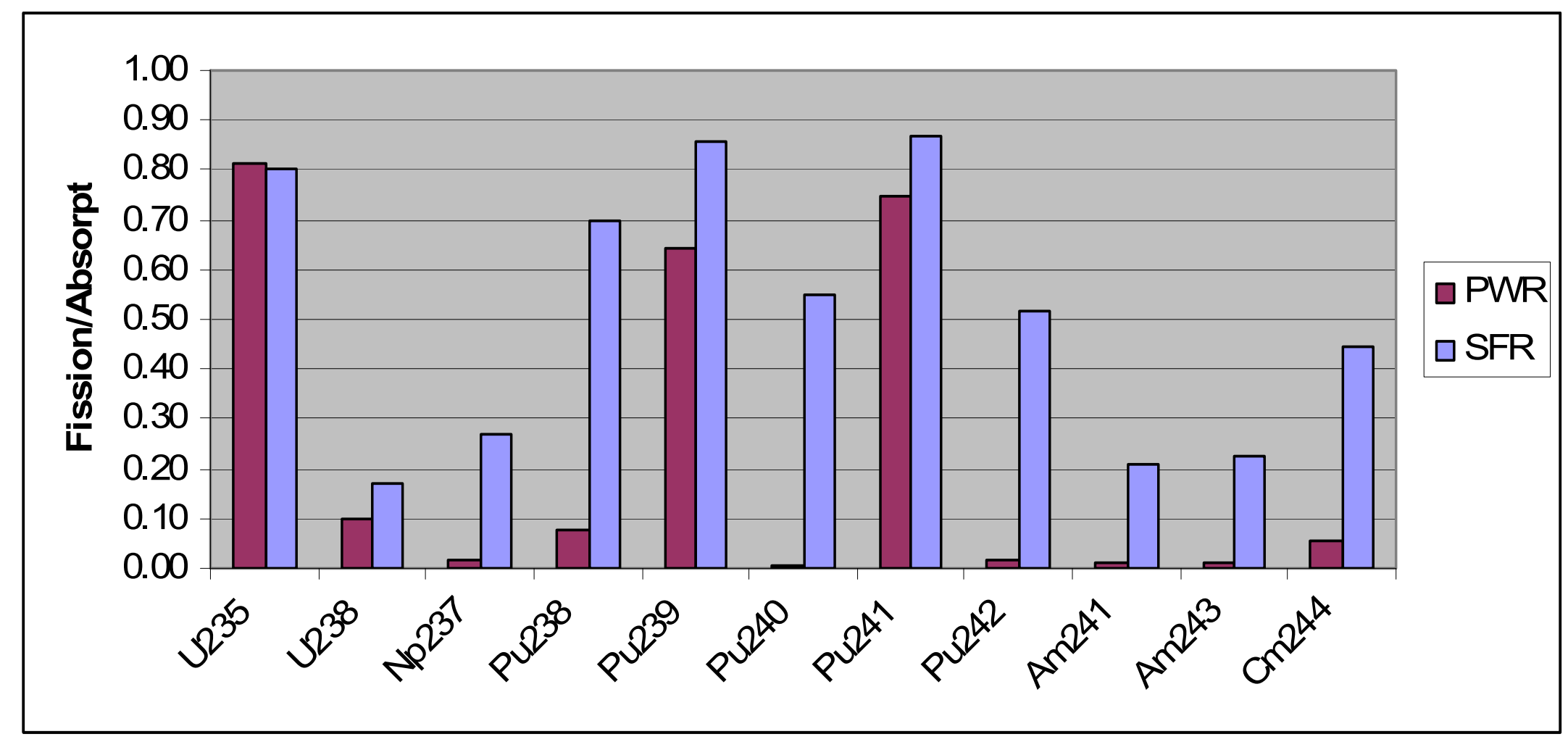

Figure 2. Fission-to-Capture Ratio for Dominant Actinides in PWR and SFR Spectra 
In the thermalized neutron spectrum, capture is the dominant reaction for a large fraction of the neutrons, except for a few isotopes, most notably Pu-239, Pu-241, and Np-237. In practice, this implies that during neutron irradiation the TRUs move up the chain illustrated in Figure 1 and create a product heavily loaded with the higher-atomic-number TRUs before eventually fissioning. Fuel cycle studies [2] indicate that these products would be very difficult to handle in practical fuel cycle installations due to the significant neutron and gamma doses emitted. In addition, the typical TRU mixture is not neutronically self-sustaining, but requires an external source of neutrons. This can be achieved by increasing the percentage of U-235 in the reactor fuel.

In contrast, transmutation in fast reactors results in a much more limited buildup of higher actinides, as fission is favored over capture. The TRUs are neutronically self-sustaining in the fast spectrum and can support a chain reaction in the reactor.

Thermal reactors are adequate for transmuting certain fissile isotopes, but are generally not considered adequate for completing the entire transmutation process, for which fast reactors are needed in the mid term. In the longer term, other means of transmutation may be of interest such as neutrons from an accelerator-driven sub-critical system and neutrons created by fusion machines.

\section{Proposed Fuel Cycles: Ongoing R\&D and Potential Challenges}

\section{System Architecture}

As discussed above, thermal reactors are able to fission a few isotopes of interest, and fast reactors are needed to fission all remaining TRUs. It is also generally agreed that thermal reactors, at least in the short term, cost less than fast reactors. These considerations lead to the choice of two system architectures (Figure 3).

- The "single-tier" systems, where all TRUs are extracted from the irradiated fuel from commercial reactors and are refabricated as fuel for a closed-cycle fast reactor.

- The "dual-tier" systems where a fraction of the TRUs (plutonium and neptunium) are partially transmuted in existing and third-generation light water reactors for a single irradiation cycle, and all remaining TRUs are irradiated in a closed-cycle fast reactor.

These two systems meet the following critical objectives:

- They minimize waste volume and radiotoxicity, as only the very small fraction of TRUs that is lost in the separations and fuel fabrication processes ends up in the waste.

- They increase energy production (normalized to initial natural resources) by fissioning the TRUs present in the irradiated fuel. This results in a minimum of $30 \%$ increase in energy production. A much more significant increase (up to a factor of 100) can be obtained by designing the fast reactors so that they convert a large fraction of the original U-238 into Pu-239 that can then be fissioned (this is achieved by modifying the 
composition of the fast reactor fuel toward higher U-238 content, and by introducing more fast reactors in the system).

The final choice between the two architectures will be made after consideration of the following elements:

- Economics: At present, economics favor the dual-tier system. Significant R\&D for fast reactors aimed at lowering costs could change this.

- Non-proliferation: Non-proliferation issues are particularly important for the dual-tier system, which may produce quasi-pure, weapons-usable elements (plutonium and neptunium).

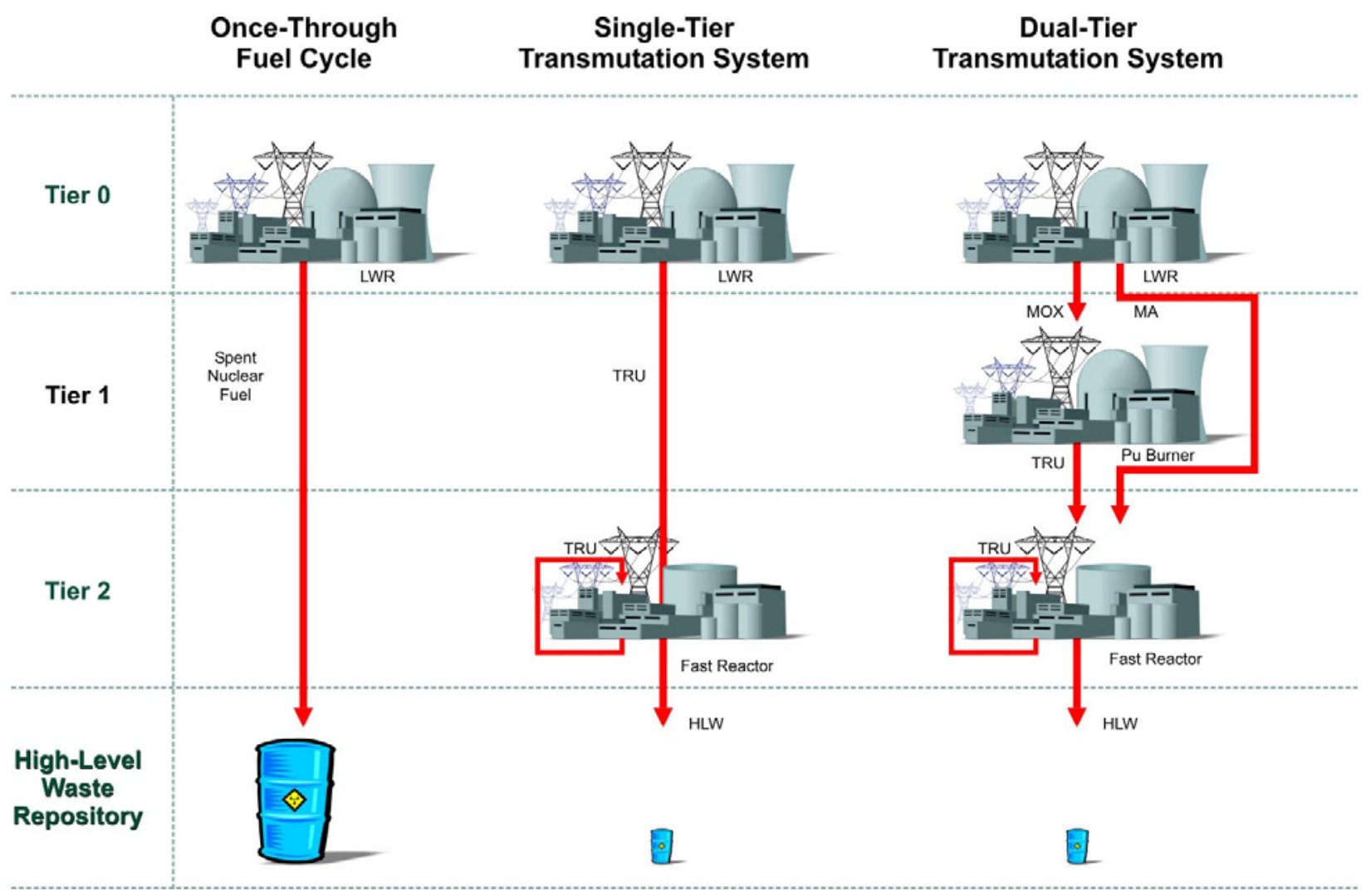

Figure 3: Transmutation System Approaches

\section{Technology Choices for Advanced Fuel Cycles}

For the purposes of this report, the objective is to deploy the proposed systems within the shortest amount of time reasonably achievable. Short of a focused, national-priority approach like the Manhattan Project, we believe that these fuel cycles can be deployed at large scale in 20 years, after completion of the research, development, and demonstration outlined below. 
Several technology choices can be made a priori on the basis of the current readiness of each technology. These choices are indicated in Table 1.

Table 1. Choices for Advanced Fuel Cycles

\begin{tabular}{|c|c|c|c|}
\hline & Single-Tier System & Dual-Tier System & Long-Term Options \\
\hline $\begin{array}{l}\text { Front-end fuels } \\
\text { separations }\end{array}$ & UREX+1a & UREX+3 & Advanced Processes \\
\hline $\begin{array}{l}\text { Thermal reactor for } \\
\text { recycle }\end{array}$ & & $\begin{array}{c}\text { LWR } \\
\text { ALWR }\end{array}$ & $\begin{array}{l}\text { Advanced light water } \\
\text { reactor, very high } \\
\text { temperature reactor }\end{array}$ \\
\hline $\begin{array}{l}\text { Fuel for thermal } \\
\text { reactor }\end{array}$ & & $\begin{array}{l}\text { Mixed oxide (MOX) } \\
\text { With UREX+1a }\end{array}$ & $\begin{array}{l}\text { Inert matrix fuel (IMF), } \\
\text { TRISO }\end{array}$ \\
\hline $\begin{array}{l}\text { Separations for fast } \\
\text { reactor fuel }\end{array}$ & $\begin{array}{l}\text { Pyroprocessing or } \\
\text { advanced aqueous }\end{array}$ & $\begin{array}{l}\text { Pyroprocessing or } \\
\text { advanced aqueous }\end{array}$ & Advanced processes \\
\hline Fast reactor fuel & Metal or MOX & Metal or MOX & $\begin{array}{l}\text { Nitrides, carbides, } \\
\text { composites }\end{array}$ \\
\hline Fast reactor & Sodium-cooled & Sodium-cooled & $\begin{array}{l}\text { Lead-cooled or gas } \\
\text { cooled fast reactor; } \\
\text { Advanced systems } \\
\text { (fusion-fission; } \\
\text { accelerator driven } \\
\text { systems, molten salt } \\
\text { reactors) }\end{array}$ \\
\hline
\end{tabular}

\section{R\&D Timeline and Potential Challenges}

Figure 4 illustrates the main components of the R\&D program that will result in largescale deployment of these fuel cycles within 20 years. Potential challenges are highlighted in bold.

\section{LWR Separations}

The UREX+ suite of processes (see Acronyms) is currently being developed at the laboratory scale in several existing facilities within the DOE complex. Results are very promising and scale-up of the processes to industrial size is expected to be feasible since a major component of the process is similar to current PUREX technology.

The process parameters will be fixed by 2014 , at which time a pilot-scale facility that is to be built will be operated at large scale. Final technology definitions will be ready in 2019 to be incorporated in a large-scale industrial plant that will be fully operational by 2025 . Several potential difficulties, however, represent challenges that have yet to be resolved. 
Figure 4. The Path to Sustainable Nuclear Energy

The First 20 Years (2005-2025)

Long-Term (2026-2040)

Multiscale Modeling with Uncertainty Propagation - Separations chemistry - More accurate nuclear data

Basic Understanding of UREX+

Basic Understanding of - Materials

Dissolution Phenomena

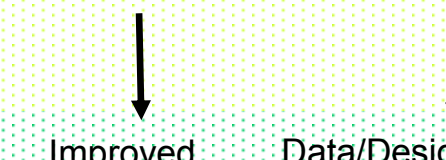

mproved Data/Design Analysis

ools and Validation

Process

Experiments

$\begin{array}{ll}\text { Waste } & \text { Cost \& Waste Reduction; } \\ \text { Reduction } & \text { Proliferation Resistance }\end{array}$

\author{
Basic Understanding
}

Basic Understanding of Radiation Effects

Separation

Lanthanides

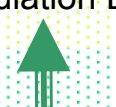

from TRU

Optimized

Separation

Processes
First-Principles Materials $\quad$ Basic Understanding of Novel Approaches Design Processes

Design of

Basic Understanding

of Fuel Behavior

Resistant Fuel

Advanced Online

Waste

Modeling

Duration of
R\&D Time Frame

Monitoring \&

Detection

Proliferation Resistance

Nanotechnologies

- Fusion
Cost \& Waste

Reduction

Complex systems

Novel Concepts

Design simplification for Fast Reactors

Balance of Plant Materials Design Margins Cost Fuel R\&Q

ssing $R \& D$

Geologic Disposal

Waste Reduction

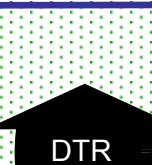

Proliferation Resistance
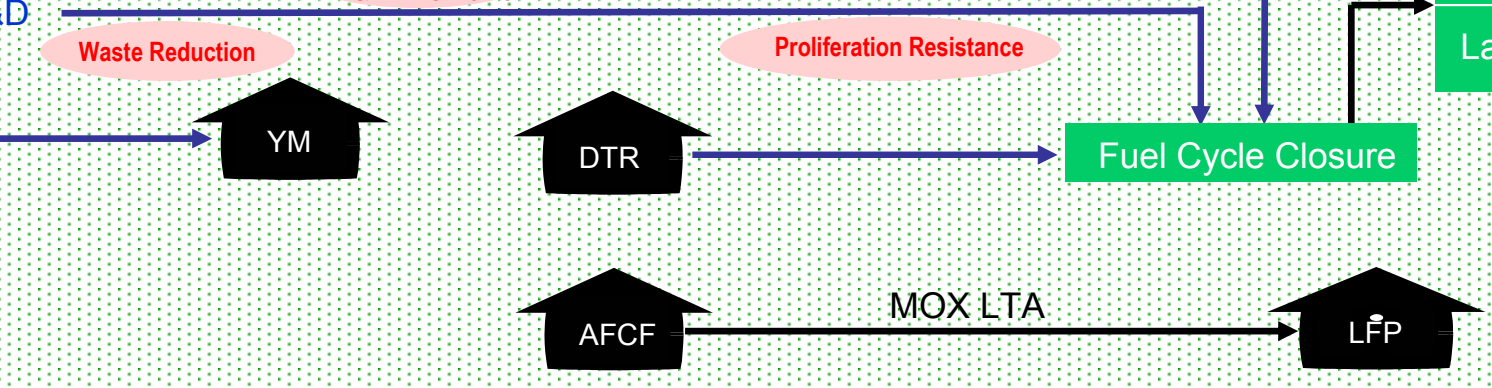

LFP

$M O X \& M F R \& D$

Duration of

R\&D Time Frame
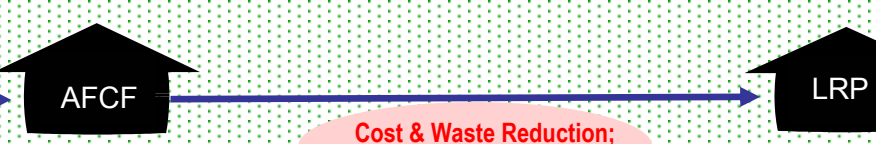

Cost \& Waste Reduction;
Proliferation Resistance

2015

2020

9

2025

Full Actinide Recycle

Legend

AFCF = Advanced Fuel Cycle Facility

CFR $=$ Commercial Fast Reactor

DTR $=$ Demonstration Test Reactor

IMF = Inert Matrix Fuel

LTA $=$ Lead Test Assembly

LFP $=$ Large Fabrication Plant

$\mathrm{LRP}=$ Large Reprocessing Plant

MOX $=$ Mixed Oxide Fuel

$\mathrm{YM}=$ Yucca Mountain

$\longrightarrow$ Advanced, FirstCost \& Waste Reduction; $\quad \begin{gathered}\text { and Analysis Tools } \\ \text { and }\end{gathered}$ Proliferation Resistance
Novel Actinide Management Technologies

Next-Generation Nuclear Energy System

Potential Showstopper

R \& B Activity
First-Principles Modeling

of Nuclear Energy

System Phenomena 
- The UREX+ processes, like all separation processes, do not achieve complete separation, and result in certain amounts of waste and effluents that must be treated, thereby raising costs, which can lessen public acceptance; the cost of these processes is often cited as an impediment to their deployment.

- The current dissolution step used at the front end of the UREX+ scheme leaves about $0.1 \%$ of the transuranic content of spent fuel undissolved, requiring the addition of cladding hull cleanup and waste stream processing steps in order to limit the TRU content of final wastes..

- If all TRUs need to be recycled directly to a thermal reactor, highly efficient TRU decontamination from fission-product lanthanides becomes important. It may be necessary to restrict thermal recycle to fuels that have cooled for very long times to reduce the $\mathrm{Pu}-241$ and $\mathrm{Cm}-242$ content; thus reliable and durable aqueous-based methods are required. (Note that it is unlikely that full TRU recycle to LWRs will ever be adopted.) For the direct recycle to fast reactors (the single tier approach), it is acceptable to carry a fraction of the lanthanides to the fuel, but partial cleanup of the TRU stream will still be required.

- Proliferation risk is also cited as an impediment to the industrial deployment of the UREX+ processes - this is particularly related to the precision limitations associated with present materials accounting systems in large industrial-scale plants.

\section{LWR Recycle}

\section{Fuel}

The AFCl program is currently considering two types of fuel for LWR recycle:

- A modification of current-technology MOX fuel, which would be used to partially transmute plutonium and neptunium. This is low-risk R\&D, but would require a considerable amount of time to be finalized because of the lack of understanding of the materials science underpinning fuels behavior. The lengthy "cook and look" approach currently used in fuels development, certification, and licensing must be shortened.

- Advanced inert matrix fuels, which would not rely on a uranium matrix (and thus would significantly reduce the production of TRUs during irradiation). Such fuels are being developed using a conventional R\&D approach involving successive irradiation tests, and will probably not be ready for at least 20 years.

- Fuel development is now on the critical path for all nuclear research, as the usual cycle length (from the launch of a program to final licensing) lasts from 15 to 20 years. The current standard empirical approach to fuels development is the root cause of this long time frame. The basic phenomena that govern fuel behavior during irradiation are poorly understood. They have been under-investigated because these phenomena are so complex and represent daunting challenges to gaining an understanding of their cumulative effects. The empirical approach must be enhanced by understanding and modeling of fuel properties and performance on the microscopic scale. 


\section{Closed Fuel Cycle}

\section{Fast Reactor Development}

There is currently very little research in the U.S. focused on sodium-cooled fast reactors, although there is significant research ongoing in Japan; the French program had significantly slowed down after 1997, but is now restarting vigorously. Fast reactors have been developed since the 1950s, with both successes (EBR-I, EBR-II, and Fast Flux Test Facility in the U.S., Rapsodie and PHENIX in France, BN-350 and BN-600 in the former Soviet Union, JOYO in Japan) and difficulties (MONJU in Japan is currently shutdown due to a sodium leak; SUPERPHENIX in France was shut down for political reasons after a series of small technical problems). The fast reactor technologies are quite mature, but less so than the light water reactor technologies that have been widely deployed.

- There is an assumed high cost incurred in building a fast reactor. While there is no R\&D on that topic in the U.S. at this point, it is strongly believed that design simplifications (for example by eliminating the secondary loop in favor of a supercritical $\mathrm{CO}_{2}$ Brayton cycle), combined with reduced design margins that could result from modern simulation tools, could significantly reduce the cost of these systems. These simulation tools do not exist at present, and represent a major opportunity for fundamental research to have an impact.

\section{Fast Reactor Fuel Cycle}

The fast reactor fuel cycle comprises two technologies: a transmutation fuel, heavily loaded with TRUs, and a specific separations technology. The reference technology at this point is metallic fuel generated by pyroprocessing. These technologies have been partially demonstrated in association with the EBR-II reactor, and R\&D is ongoing within the AFCl program. Some significant challenges remain for both fuel and pyroprocessing technologies.

- The major difficulty is similar to the one discussed for LWR recycle fuels: due to the lack of fundamental knowledge of fuel behavior phenomena, the development approach has been very empirical and, consequently, very slow. This difficulty is compounded in the U.S. by the lack of large-scale fast neutron irradiation facilities.

- The losses of TRUs to the various waste streams need to be kept very low, comparable to losses for processing of LWR spent fuel, but loss mechanisms are not yet fully understood.

- The impurity levels in the streams are not yet fully understood; lanthanides decontamination requirements may require the use of aqueous processing methods to reduce the lanthanide content of the recycle fuel stream.

- Relatively high-temperature operational environments are required, possibly resulting in high-temperature materials issues leading to equipment changeout and replacement (thereby adding to waste streams and costs).

- The cost of the process must be kept low, and significant optimization work is needed. Modeling of the complete pyroprocessing operation must be validated by experiments with representative fuel compositions. 


\section{Potential Contributions of Basic Scientific Research to Advanced Fuel Cycle Initiative Technologies}

One of the fundamental outcomes of our workshop is the clear understanding of the need to establish strong interaction tools between engineers and scientists. Many scientists strive to create basic understanding of phenomena, whereas many engineers strive to create cutting-edge products that are a solution to a practical problem. From one side, the fundamental understanding may not be directly translated to product development, and from the other side, the needs of product engineering may not be immediately translated into identifying the scientific breakthroughs that are needed.

We introduce the concept of "translational tools," a series of techniques that can span the gap between engineering and basic science, absorb the knowledge produced by the scientists, and put it in a form directly usable by the engineers (Figure 4). The same approach will be used (via sensitivity analyses) to translate engineering needs into basic science needs (a formalized approach based on sensitivity analyses has been successfully used in the past for defining nuclear data needs).

\section{Translational Tools Needed to Advance AFCI Objectives}

The first category of tools represents validated (via key experimental data) advanced simulation systems that can be used to:

- Design reactors with reduced margins (redundancies, conservatism in design choices, etc.) enabled by a more streamlined and economical pathway from design to prototype to demonstration facility;

- Design reprocessing plants to achieve reduced waste streams, lower costs, equipment simplifications, etc.;

- Design monitoring processes to more accurately describe material flows, holdups, losses, etc. so as to optimize nuclear materials accounting;

- Model expected fuel behavior, including burnup, discharge of isotopes, possible failure mechanisms and ramifications, etc.;

- Model other materials issues (stress, corrosion, radiation damage, activation, thermal conductivity, new phase formation, etc.)

- Model separations processes to optimize performance, better understand degradation of reagents and components, minimize energy input, and reduce waste stream production.

The second category represents directed research activities that focus on creation of more fundamental scientific understanding of key phenomena or that can lead to new performance opportunities

- Design of detectors:

o For real-time, on-line monitoring of separations processes (including radionuclides for materials accounting, and process solvents and extractants to check for degradation) 
o For monitoring in-core or ex-core components of reactors to verify performance as well as to warn of possible fault conditions;

- Materials

o For robust, corrosion-resistant waste forms

o For high-performance fuel forms and materials of construction

o For extended-life reactors

- New or advanced processes

o For minimizing losses in nuclear materials operations (separations, fuel fabrication) and for optimizing performance while simplifying complexity of operation

Both categories of these translational tools are analogous to approaches used by other major programs, for example, NNSA's Stockpile Stewardship program with its Accelerated Strategic Computing Initiative component (directed toward advanced computing and simulation), National Ignition Facility (experimental facilities development) and supported university research programs (Academic Strategic Alliance).

\section{Potential Impacts of Translational Tools on AFCI Challenges}

Replacing Edisonian approaches (empirical methods) for fuels development and validation with science-based prediction. More complete understanding of fuel properties and performance, particularly on the microscopic scale, could significantly reduce the number of experimental irradiations required, could tailor chosen experiments to achieve maximum information needed for performance prediction, and should reduce the time for design, synthesis, and development of new fuels from $\sim 15$ years to $\sim 5$ years.

Development of improved materials for utilization in nuclear systems. Better understanding of materials performance in nuclear environments (radiation, corrosion, thermal stresses) could lead to tailored materials that in turn would impact system longevity, waste stream production, and operational safety.

Improved understanding of separations chemistry and identification of advanced separations approaches. Progress in such areas could significantly reduce chemical waste generation, thereby reducing adverse environmental impacts and overall system costs (since a major fraction of the costs of a large reprocessing plant are directed toward material recycle, waste disposal, etc).

Advanced reactor and fuel cycle facility design capabilities. Advanced simulation capabilities could replace empiricism in design, thereby reducing conservatism while increasing performance, safety, etc. Such capabilities could reduce the number and the overall cost of "big-ticket" facilities traditionally required in full-scale engineering development and demonstration efforts.

Improved detectors and monitoring capabilities that allow continuous, real-time knowledge of systems operations and performance. New detectors coupled with fast, largescale data handling could achieve rapid in-situ monitoring for remote detection of potential 
equipment or process failure, increasing the resistance of the system to diversion of special nuclear materials.

\section{Science Areas That Impact the Advanced Fuel Cycle Initiative}

The four broad, interrelated science areas that impact the $\mathrm{AFCl}$ and the implementation of advanced nuclear fuel cycles are materials, separations, modeling and simulation, and proliferation resistance of the overall fuel cycle.

\section{Materials}

Maximizing the efficiency of nuclear fuel use, minimizing the effects of disposed wastes, and limiting the proliferation risks associated with the fuel cycles are the challenges related to materials science. To provide optimum fuels, structural materials, waste forms, and materials systems for separations and safeguards, the behavior of materials must be understood at a level of fundamental knowledge and predictability that allows for reduction in margins and costs. Materials-crystalline, amorphous, organic, inorganic, metallic-are required in all stages of the nuclear cycle. These materials form complex multi-component dynamic systems that evolve in time under a wide range of conditions including high radiation fields, high temperatures, and harsh chemical environments. Fundamental understanding of the properties of structural and nuclear materials is essential to predicting their long-term behavior and can only come about through closely coupled theory, modeling and experimentation.

The scientific challenges facing materials development for AFCl fall into three primary areas of need:

- Thermodynamic and thermophysical properties; in particular:

o Multi-scale theoretical frameworks to predict thermodynamic equilibrium phases of complex alloys and compounds at reactor-relevant temperatures, in waste form storage environments, and in separation plants. In particular, the behavior of elements present in trace concentrations (e.g., actinides) must be described accurately using physically meaningful formalisms.

o Models based on first-principles physics and statistical mechanics, accompanied by accurate measurements of key parameters.

- Solid/solid, liquid/liquid, and solid/liquid interface interactions; in particular:

o Theoretical frameworks to predict phases formed and growth kinetics for complex oxides, dissolution from ceramic phases, and formation of eutectics

o Models from first principles for electrochemical phenomena, accompanied by accurate measurements of key parameters

o Multiscale models of the response of materials and materials systems to environmental and chemical conditions used in separations and on-line sensing

- Radiation effects in complex materials

o Multi-scale thermo-kinetic theoretical frameworks for the co-evolution of all components of microstructure under radiation, especially at high temperature. 
These frameworks must include reactor-relevant temperatures and dose rates, for prototypical reactor damage mechanisms

o Multiscale theoretical frameworks and understanding of materials response to individual radiation interaction events (radiation detector physics) from the level of electrons and atoms to the response of coupled materials systems

o Establishment, validation, and verification of these theoretical frameworks through accurate measurement of key parameters

\section{Separations}

In the context of $\mathrm{AFCl}$, the initial technical approach for the separation of uranium from the other actinides and fission products has been achieved through the suite of solvent extraction processes collectively referred to as the Uranium Extraction Plus process (UREX+).

There are a number of areas of fundamental chemical science whose advancement could have substantial impact both on the intermediate-term development of the current generation of separations processes and on the creation of revolutionary new approaches to more efficient, cleaner processes for the next generation. These fundamental topics for investigation cross-cut broad areas of the nuclear fuel cycle, from fuel dissolution, through separation, to waste disposal and repository performance. It is expected that full development of these scientific areas will create the opportunity for comprehensive science-based design of a reprocessing plant that includes a completely integrated waste management system to partition actinides, lanthanides, fission products, cladding materials, etc.

This science will minimize environmental impacts-that is, almost no transuranium elements (TRUs) will be sent to the repository; long-lived fission products will be separated for ultimate transmutation or incorporation into robust waste forms; minimal secondary waste will be created; waste volume and heat load on repository will be minimized; only proliferation-resistant streams containing nuclear materials will be created; and the overall process will be energyefficient, economical, safe, and have as small a footprint as is possible. Partitioning of wastes will also create opportunities to tailor the waste form to the species targeted for disposal, resulting in increased probability of retention of wastes within the boundaries of a geologic repository for the necessary length of time.

Enough is known about each of these topics to recognize the needs. At the present level of understanding of the fundamental science, achievement of all of these important objectives remains a major challenge.

In the long term, completely new approaches involving novel materials may be identified. Among the more radical materials being investigated now, supercritical $\mathrm{CO}_{2}$, room-temperature ionic liquids, aqueous biphases, membranes, and volatility are systems with promise. Magnetic/electrostatic external fields applied to fluids and hybrid systems (for example, mixing hydro- and pyrometallurgical methods) have added potential for impact. Design and synthesis 
of chemical reagents that can encapsulate selected radionuclides ("switched on") and then after the separation can be "switched off" by external means (e. g., light pulse) to release the radionuclide would effect the separation and generate no additional chemical waste.

One common problem for each of these methods is the relatively primitive understanding of solvation and solubility phenomena that must be overcome. The following research topics are suggested as initial focal points that will have substantial impact on the introduction of new research approaches, while advancing the understanding and improvement of the better-known aqueous and pyrochemical processes. These will be accomplished by a combined experimental and modeling effort.

- Understanding molecular and supramolecular behavior of multicomponent fluids

- Design, synthesis, and characterization of specific receptors for selective separations

- Understanding interfacial phenomena and their impact on mass transfer between phases

- Understanding and controlling radiation effects in separations processes

\section{Modeling and Simulation}

These topics are now considered to be the third branch of science, bridging experiment and analytical theory. The role of simulation in modern scientific and technical endeavors cannot be underestimated, and the use of effective modeling and simulation plays a critical role in modern scientific advances. Modeling, theory and simulation can enhance our understanding of known systems, can provide qualitative/quantitative insights into experimental work, and can guide the choice of the experimental system to study or enable the design of new systems. This is most useful if the simulation has been benchmarked experimentally on well-established systems to validate the approach. Finally, simulations can provide quantitative results to replace experiments that are too difficult, dangerous or expensive and can extend limited experimental data into new domains of parameter space. Because of the difficulties in dealing with radioactive materials, modeling and simulation will play a play a critical role in advancing our nuclear research programs.

The analytical demands of next-generation reactors are unique and severe, requiring advanced transport methods for radiation, heat, and fluid flow. These demands are complicated by rapidly changing hardware and software development environments, making it difficult to develop robust, modern transport codes that efficiently utilize the available computational resources. These efforts entail modeling over a large range of scales, from the subatomic to the macroscopic. Devising methods and models that can accurately describe the physics over these disparate scales is a significant challenge that is currently unmet. Visualizing, interpreting, and displaying the results of multiscale analyses also present great difficulties, not only because of the multiscale nature of the data, but also because of the massive volume of data to be analyzed. An additional challenge is data sharing and inter-code communication as well as dealing with the human interface factor, real-time monitoring, sensing, and control based on advanced simulations. The analysis of nuclear energy generation plants entails coupling codes that operate at different scales and are likely to not share common data definitions or common 
physical models. The integration of these codes is essential to enable these analyses to be performed smoothly and efficiently.

Ongoing modeling and theoretical work on nuclear data, materials modeling and separations science, especially if efforts are expanded, are expected to have significant impact in the short term (5 to 10 years) while new developments in modeling and simulation will have the biggest impact on fast reactors on a long-range time scale (> 20 years).

The critical needs of modeling at present are methods to deal with multi-scale physics in terms of different models and widely varying temporal and spatial scales, and methods to deal with uncertainties including propagation of errors in data and in models

The scientific challenges facing modeling and simulation for $\mathrm{AFCl}$ fall into these primary areas:

- Nuclear data: Improve nuclear data covariance matrices, determine precise actinide cross sections

- Materials design and behavior: Model materials in extreme environments, including high radiation fields and elevated temperatures

- Modeling for design of new separation systems: Advanced separations associated with minimizing waste from spent fuel

- Multi-scale modeling with uncertainties: Model entire fuel cycle with propagation of uncertainties in the data and the models

\section{Proliferation Resistance of the Overall Nuclear Cycle}

Current nuclear fuel management practices, both open cycle and closed cycle, present inherent proliferation risks. Whereas the theft or diversion of highly radioactive fresh spent fuel in a "once through" model is dangerous and difficult, decay of the fission products over time increases the accessibility and retrievability of the plutonium after 50 to 100 years. The U.S. has become increasingly concerned about the continued global accumulation of plutonium in spent fuel and as separated plutonium, which presents a growing proliferation risk worldwide (the accumulated civilian quantities of separated plutonium in storage may soon surpass military stockpiles). In seeking to minimize the environmental impact of nuclear energy, other nations have begun to implement reprocessing of spent fuel (both to minimize waste storage requirements and to recover the economic value of uranium and plutonium). The most common reprocessing scheme employed in Europe and planned in Asia (employing the PUREX process) generates quantities of separated plutonium that have accumulated because the use of plutonium in MOX fuel has not kept pace with the plutonium production operation and the limited number of MOX recycles. This fissile material may be susceptible to theft and diversion.

New capabilities are needed in the global management of nuclear materials. Unfortunately, there is no universal metric of responsible materials management against which to measure improvements, but a number of factors can be cited as targets for improvement. One could argue that there are several "top level" goals that could benefit from application of new science and technology: 
- Strengthening safeguards technology (improving means of evaluating and quantifying materials throughput to reduce risk of diversion through advanced radiation monitoring detection systems, specific sensors to monitor chemical process conditions and chemical effluents).

- Decreasing the attractiveness of nuclear materials in fuels and bulk materials (reducing the purity of fissile material in isotopic and chemical composition).

- Controlling and optimizing management of total inventories of nuclear materials (limiting total quantities/availability of fissile materials, perhaps by optimizing the composition of fuels to balance performance with proliferation resistance).

\section{REFERENCES}

1. Personal communication, Professor Saito, Tokyo Institute of Technology

2. Advanced Fuel Cycle Initiative (AFCI) Program Plan, U.S. Department of Energy, May 1, 2005 


\section{ACRONYMS}

\begin{tabular}{|c|c|}
\hline $\mathrm{AFCl}$ & Advanced Fuel Cycle Initiative \\
\hline FR & Fast reactor \\
\hline LWR & Light water reactor \\
\hline MOX & Mixed oxide fuel \\
\hline PUREX & Plutonium Uranium Extraction process \\
\hline PWR & Pressurized water reactor \\
\hline $\mathrm{R} \& \mathrm{D}$ & Research and development \\
\hline SFR & Sodium-cooled fast reactor \\
\hline TRISO & "Tri-isotropic" particle fuel for gas cooled reactors \\
\hline TRU & Transuranic elements \\
\hline UREX & Uranium Extraction process \\
\hline UREX+1 & $\begin{array}{l}\text { Variant of UREX+ to separate uranium, technetium, cesium/strontium, } \\
\text { transuranics/lanthanides, and fission products }\end{array}$ \\
\hline UREX+1a & $\begin{array}{l}\text { Variant of UREX+ to separate uranium, technetium, cesium/strontium, } \\
\text { transuranics, and all fission products }\end{array}$ \\
\hline UREX+2 & $\begin{array}{l}\text { Variant of UREX to separate uranium, technetium, cesium/strontium, } \\
\text { plutonium+neptunium, americium+cesium+lanthanides, and fission products }\end{array}$ \\
\hline UREX+3 & $\begin{array}{l}\text { Variant of UREX to separate uranium, technetium, cesium/strontium, } \\
\text { plutonium+neptunium, americium+curium, and all fission products }\end{array}$ \\
\hline UREX+4 & $\begin{array}{l}\text { Variant of UREX to separate uranium, technetium, cesium/strontium, } \\
\text { plutonium+neptunium, americium, cesium, and all fission products }\end{array}$ \\
\hline VHTR & Very High Temperature Reactor \\
\hline
\end{tabular}


The Path to Sustainable Nuclear Energy

Basic and Applied Research Opportunities for Advanced Fuel Cycles

September 12-14, 2005

\section{Background}

In response to a request from the Director of the Office of Science of the U.S. Department of Energy, a small workshop was convened to summarize the scientific basis, technology challenges, and basic and applied research needs that could impact the design of nuclear fuel cycles which strive to minimize waste, minimize long-lived radioisotopes, and maximize energy output.

Workshop Organizers and Participants

Co-chairs

Phillip Finck, Argonne National Laboratory, pfinck@anl.gov

Norman Edelstein, Lawrence Berkeley National Laboratory, nmedelstein@lbl.gov

Participants

$\begin{array}{lll}\text { Todd Allen } & \text { University of Wisconsin, Madison } & \text { allen@engr.wisc.edu } \\ \text { Carol Burns } & \text { Los Alamos National Laboratory } & \text { cjb@lanl.gov } \\ \text { Mark Chadwick } & \text { Los Alamos National Laboratory } & \text { mbchadwick@lanl.gov } \\ \text { Michael Corradini } & \text { University of Wisconsin, Madison } & \text { corradini@engr.wisc.edu } \\ \text { David Dixon } & \text { University of Alabama, Tuscaloosa } & \text { dadixon@bama.ua.edu } \\ \text { Mike Goff } & \text { Idaho National Laboratory } & \text { mike.goff@inl.gov } \\ \text { James Laidler } & \text { Argonne National Laboratory } & \text { laidler@cmt.anl.gov } \\ \text { Kathryn McCarthy } & \text { Idaho National Laboratory } & \text { Kathryn.Mccarthy@inl.gov } \\ \text { Bruce Moyer } & \text { Oak Ridge National Laboratory } & \text { moyerba@ornl.gov } \\ \text { Ken Nash } & \text { Washington State University, Pullman } & \text { knash@wsu.edu } \\ \text { Alexandra Navrotsky } & \text { University of.California, Davis } & \text { anavrotsky@ucdavis.edu } \\ \text { Pavel Oblozinsky } & \text { Brookhaven National Laboratory } & \text { oblozinsky@bnl.gov } \\ \text { Kemal Pasamehmetoglu } & \text { Idaho National Laboratory } & \text { kemal.pasamehmetoglu@inl.gov } \\ \text { Per Peterson } & \text { University of California, Berkeley } & \text { peterson@nuc.berkeley.edu } \\ \text { John Sackett } & \text { Argonne National Laboratory } & \text { johnisackett@aol.com } \\ \text { Kurt E.Sickafus } & \text { Los Alamos National Laboratory } & \text { kurt@lanl.gov } \\ \text { James Tulenko } & \text { University of Florida, Gainsville } & \text { tulenko@ufl.edu } \\ \text { William Weber } & \text { Pacific Northwest National Laboratory } & \text { bill.weber@pnl.gov } \\ \text { US DOE Contacts } & & \\ \text { Lester Morss, Office of Basic Energy Sciences, 301-903-9311, lester.morss@science.doe.gov } \\ \text { Gene Henry, Office of Nuclear Physics, 301-903-6093, gene.henry@science.doe.gov }\end{array}$

